\title{
Real time implementation of a super twisting control of a BLDC motor
}

\author{
Ali Mousmi, Ahmed Abbou, Yassine El Houm, Anass Bakouri \\ Department of Electrical Engineering Mohamed V University, Mohammadia School's of Engineers, ROC
}

\begin{tabular}{|c|c|}
\hline Article Info & ABSTRACT \\
\hline Article history: & \multirow{9}{*}{$\begin{array}{l}\text { This paper presents and implements a Super-Twisting high order sliding } \\
\text { mode control for a BLDC motor. Conventional sliding mode controller has a } \\
\text { very fast response, it allows the convergence in finite time and characterized } \\
\text { by its robustness against disturbances and uncertainties; However, } \\
\text { the chattering phenomenon due to the discontinuous nature of its control } \\
\text { organ degrades its performance, especially in case of mechanical membranes } \\
\text { control. To overcome this disadvantage, the most commun solutions are } \\
\text { based on the adaptation of its discontinuous nature at static regime, it reduces } \\
\text { effectively the chattering phenomenon, but on the other hand impacts } \\
\text { performance in terms of robustness. The Super-Twisting is an algorithm of } \\
\text { high order sliding mode applicable on systems with relative degree } 1 \text {, } \\
\text { it produces a continuous control which cancels the chattering phenomenon } \\
\text { and preserve all traditional sliding mode command performances. To validate } \\
\text { the effectiveness and the robustness of the Super-Twisting controller for } \\
\text { controlling brushless motors, experimental results using a 3KW BLDC motor } \\
\text { are provided and compared with those of a conventional sliding mode } \\
\text { controller. }\end{array}$} \\
\hline Received Sep 28, 2018 & \\
\hline Revised Mar 21, 2019 & \\
\hline Accepted Apr 4, 2019 & \\
\hline Keywords: & \\
\hline BLDC motor & \\
\hline Sliding mode control & \\
\hline Speed control & \\
\hline Super twisting algorithm & \\
\hline
\end{tabular}

Copyright $(0) 2019$ Institute of Advanced Engineering and Science. All rights reserved.

\section{Corresponding Author:}

Ali Mousmi,

Department of Electrical Engineering,

Mohamed V University, MohammadiaSchool's of Engineers,

Avenue Ibn Sina B.P 765, Agdal -Raba, Morocco, ROC.

Email: amousmi@gmail.com

\section{INTRODUCTION}

Brushless motor finds an important place in several fields, it becomes the preferred type in high speed applications and the first choice in electric vehicles sector [1,2]. This motor is a part of permanent magnet synchronous motors family, it has the same operating principle of the separately excited DC motor with the replacement of the commutator/brushes system by an electronic circuit, which gives it a compact shape and eliminates sparks (this gives it an access to the environments with explosion risk). The torque intensity and the high speed response is an indisputable advantage of BLDC motor compared to other motors families [3]. To benefit from this property, the establishment of a quick controller is a necessity, taking into account its non-linear nature, parametric variations and disturbances of which it may suffer.

In literature, different control strategies were applied for BLDCM speed control, i.e.,-the typical PID controller [4] which presents limits against parametric uncertainties [5] and needs a linear mathematical model of the controlled system. -Smart methods, eg, particle swarm algorithm [6] and fuzzy logic controller [7], this type requires only an expertise to develop a controller without needing the system model, it ensures good static accuracy and a zero overshoot. However, the speed reponse is not fast enough and its implementation needs expensive hardware. - The first order sliding mode control (SMC) $[8,9]$ is very good in terms of response time, parameters variation, external disturbances [10] and it ensures convergence in finite time [11,12], in addition, it is very simple to be implemented in any low cost materieal. Despite these 
robustness properties which make SMC the most suitable for controlling a brushless motor, its major disadvantage limits its use, it consist on the so-called Chattering phenomenon [13] due to its discontinuous control membrane, it generates indiserable effects at actuators level and can even cause instability by exciting neglected (high frequency) dynamics of the studied system. To overcome this problem of conventional sliding mode controllers, there are several methods where the most commun consists on replacing the sign function by a continuous approximation in vicinity of the sliding surface [14], or using the equivalent command [11], but the most interesting way is to use high order sliding modes.

This paper develop and implement in real time a fast and robust controller using the Super-Twisting algorithm [15] for speed control of a BLDC motor. The Super-Twisting sliding mode controller (STSMC) is a nonlinear controller that is a part of variable structure controllers, it is based on the high order sliding mode theory, in order to remedy the chatering problem of classical sliding mode controllers, canceling also the upper derivatives of the sliding surface [16-18]. In fact, this information on the derivative is unpleasant for automation specialists. So, in 1993 A. levant introduced the SuperTwisting algorithm that just requires information on the sliding variable and it is applicable on systems with relative degree 1 . This controller has been used successfully in electrical machines control, induction machine [19], DFIG [20], and development of state observers for non-linear systems [21].

The paper is organized as follows: the second section presents the brushless motor model and its operating principle. The third section presents the Super-Twisting algotithm theory and determines the brushless motor control law using this command type. The last section presents and discutes the experimental results applied on a Brushless motor of $3 \mathrm{KW}, 80 \mathrm{~V}, 3000 \mathrm{rpm}$.

\section{MODELING OF BRUSHLESS DC MOTOR}

The equivalent model of the BLDCM drive system with the assumption of three-phase symmetric stator windings is shownin Figure 1.

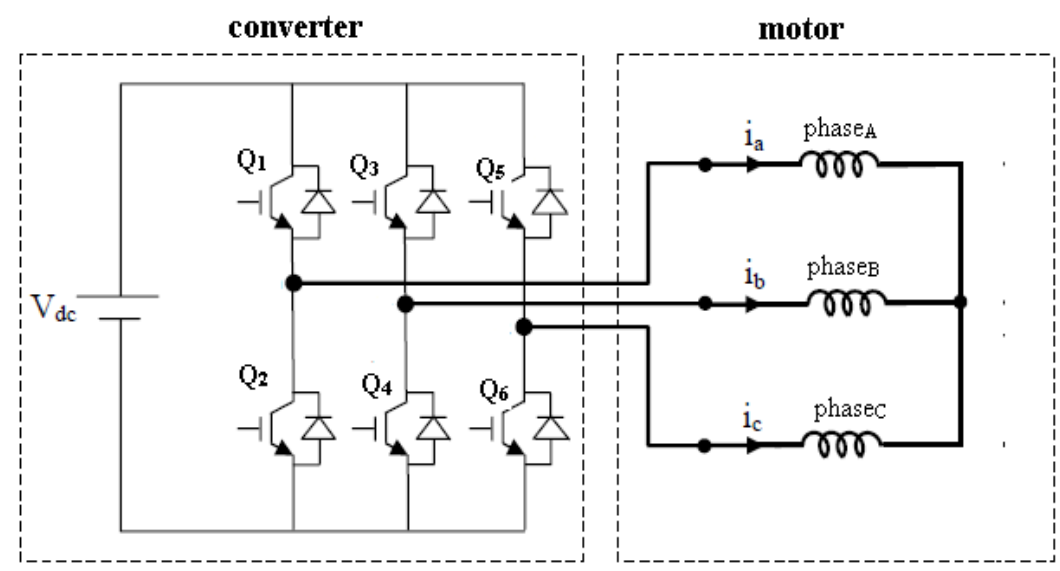

Figure 1. The full bridge driving circuit of BLDC motor

The terminal voltage equation of three-phase stator windings is expressed as:

$$
\begin{aligned}
& \left\{\begin{array}{l}
V_{a}=R i_{a}+L \frac{d i_{a}}{d t}+e_{a} \\
V_{b}=R i_{b}+L \frac{d i_{b}}{d t}+e_{b} \\
V_{c}=R i_{c}+L \frac{d i_{c}}{d t}+e_{c}
\end{array}\right. \\
& T_{e m}=\frac{e_{a} i_{a}+e_{b} i_{b}+e_{c} i_{c}}{\Omega}
\end{aligned}
$$


where $R$ is the stator resistance, $\mathrm{L}$ is the stator inductance, $\mathrm{V}_{\mathrm{a}}, \mathrm{V}_{\mathrm{b}}$ and $\mathrm{V}_{\mathrm{c}}$ are the terminal voltages of the three-phase stator winding respectively; $i_{a}, i_{b}$ and $i_{c}$ are the stator currents; $e_{a}, e_{b}$ and $e_{c}$ are the phase back EMFs; $\mathrm{T}_{\mathrm{em}}$ and $\Omega$ represent electromagnetic torque and rotor angular velocity respectively.

The controlled brushless DC motor consists of a three phase windings stator which are star connected and a permanent magnet rotor Figure 1. The motor is operating in two phases conduction mode in which each phase voltage is energized for an interval of 120 electrical degrees according to rotor electrical position. Basically, there are six different sectors, in which just two phases are powered; one is connected to the positive terminal of the $\mathrm{DC}$ bus $+\mathrm{V}_{\mathrm{DC}}$ and the other to $-\mathrm{V}_{\mathrm{DC}}$, Figure 2. The rotor position is determined using three Hall Effect sensors installed in the stator with a shift of 120 electrical degrees. Figure 2 shows the different possibilities to supply the motor according to the rotor position.

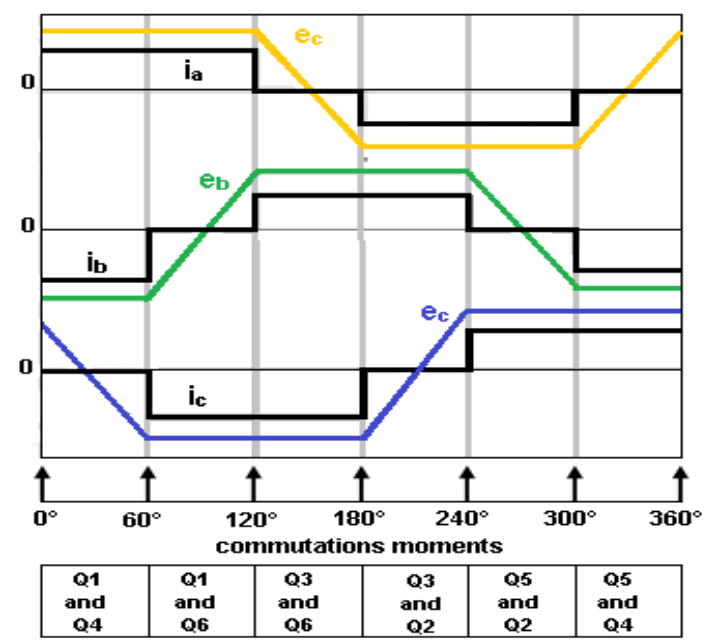

Figure 2. Six steps switching sequence

\section{BLDC MOTOR CONTROL SCHEME}

\subsection{Simplification of the model}

The electric model of the brushless motor Figure 3, and different power supplies of the stator phases depending on the rotor position are given respectively in Table 1.

Table 1. Truth table of hall effect sensors and gate state

\begin{tabular}{cccccccc}
\hline \multirow{2}{*}{ Seq } & \multicolumn{3}{c}{ Hall Sensors } & Active & \multicolumn{3}{c}{ Phases currents } \\
& C & B & A & switches & C & B & A \\
\hline 1 & 1 & 0 & 1 & Q1-Q4 & OFF & DC- & DC+ \\
2 & 1 & 0 & 0 & Q5-Q4 & DC+ & DC- & OFF \\
3 & 1 & 1 & 0 & Q5-Q2 & DC+ & OFF & DC- \\
4 & 0 & 1 & 0 & Q3-Q2 & OFF & DC+ & DC- \\
5 & 0 & 1 & 1 & Q3-Q6 & DC- & DC+ & OFF \\
6 & 0 & 0 & 1 & Q1-Q6 & DC- & OFF & DC+ \\
\hline
\end{tabular}
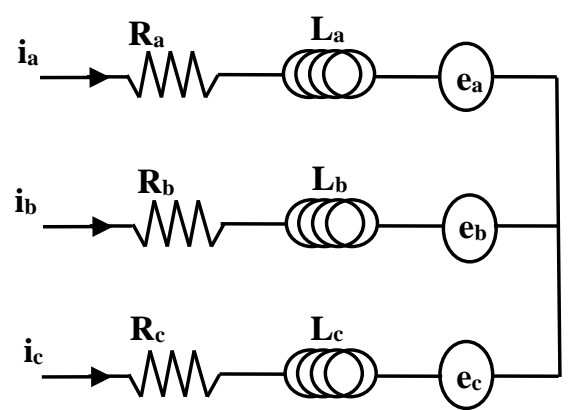

Figure 3. The BLDC motor circuit 
Consider the first sequence characterized by:

$$
\left\{\begin{array}{l}
i_{a}=-i_{b}=I, i_{c}=0 \text { with } U_{a b}>0 \\
e_{a}=-e_{b}=K_{e} \Omega=E_{m}
\end{array}\right.
$$

The three phases of the motor are symmetrical $\mathrm{R}_{\mathrm{a}}=\mathrm{R}_{\mathrm{b}}$ and $\mathrm{L}_{\mathrm{a}}=\mathrm{L}_{\mathrm{b}}$. So:

$$
\begin{aligned}
& V_{a}=R_{a} I+\left(L_{a}-M\right) \frac{d I}{d t}+e_{a} \\
& V_{b}=R_{b} I+\left(L_{b}-M\right) \frac{d I}{d t}+e_{b}
\end{aligned}
$$

where $M$ is the mutual stator inductance. Thus the expression of $U_{a b}$ is:

$$
U_{a b}=V_{a}-V_{b}=2 R_{a} I+2\left(L_{a}-M\right) \frac{d I}{d t}+2 E_{m}
$$

Posing

$$
R=2 R_{a}, L=2\left(L_{a}-M\right) \text { and } E=2 E_{m}
$$

We obtain the same expression of theDC motor electrical equation:

$$
U_{a b}=R I+L \frac{d I}{d t}+E
$$

In the same way, studying the other zones, lead to the electrical equation of a DC motor. The control of the self-driven BLDC motor is therefore similar to a separately excited DC motor where the speed is directly proportional to the voltage applied to the motor terminals; And to change this voltage, we attack the inverter arms by a PWM signal of which we vary the duty cycle to obtain the desired voltage and the desired speed accordingly.

\subsection{Super twisting algorithm}

Super twisting is an algorithm that is a part of high order sliding mode controllers; it is applied on systems of relative degree 1, whose disturbance is Lipschitz. Its main interest is the reduction of the chattering phenomenon thanks to the absence of the discontinuous term, which ensures the control signal continuity. The expression of this command is made up of summation of a non-dynamic algebraic and an integral terms. The Super Twisting algorithm causes the cancellation of the sliding variable $\mathrm{S}$ and its derivative in finite time by only requiring the information on the sliding variable.

The synthesis of high order sliding mode commands Isbased on the homogeneity approach [16, 17]. This property is satisfied by almost all high order sliding mode controls, and is the cornerstone of associated convergence proofs. As the case of the first sliding mode command law synthesis, the sliding surface $\mathrm{S}$ is chosen such that the control appears at its first derivative, generally, we choose a linear function:

$$
\begin{aligned}
& \mathrm{S}(\mathrm{e}, \mathrm{t})=\sum_{0}^{\mathrm{n}-1} \mathrm{c}_{\mathrm{i}} \mathrm{e}^{\mathrm{i}} \\
& \alpha^{\mathrm{n}-1}+\mathrm{c}_{\mathrm{n}-2} \alpha^{\mathrm{n}-2}+\ldots+\mathrm{c}_{l} \alpha=0
\end{aligned}
$$

where $e=y-y_{\text {ref }}$ and $c_{n-1}=1$

The coefficients $c_{i}$ are chosen in such a way that the polynomial(10)is a polynomial of Hurwitz. Thus, when the slip variable $\mathrm{S}(\mathrm{e}, \mathrm{t})$ is forced to zero, the tracking error converges asymptotically to zero, 
with a dynamic imposed by the choice of the coefficientsc $c_{i}$. Then, if the system satisfies the following differential inclusion:

$$
\left\{\begin{array}{l}
\dot{S} \in \sigma+\left[C_{m}, C_{M}\right] \cdot u \\
\dot{\sigma} \in[-K, K]
\end{array}\right.
$$

To drive the surface function to zero in finite time and keep it there, considering $\sigma$ as a disturbance, the commande $\mathrm{u}(\mathrm{t})$ is designed as follows:

$$
\left\{\begin{array}{l}
\mathrm{u}(\mathrm{t})=\mathrm{u}_{\mathrm{I}}(\mathrm{t})-\lambda_{1} \sqrt{\mathrm{L}} \sqrt{|\mathrm{S}| \operatorname{sign}(\mathrm{S})} \\
\dot{\mathrm{u}}_{\mathrm{I}}=-\lambda_{2} \operatorname{Lsign}(\mathrm{S})
\end{array}\right.
$$

with :

$$
\mathrm{L}=\frac{\mathrm{K}}{\mathrm{C}_{\mathrm{m}}}, \lambda_{1}>\sqrt{-2 \lambda_{2}+2 \sqrt{\lambda_{2}^{2}+2 \lambda_{2}+2}} \text { and } \lambda_{2}>1
$$

Commonly used values are: $\lambda_{1}=2$ and $\lambda_{2}=1.1$.

\subsubsection{Determination of the motor BLDCcontrol law}

Considering the first sequence, where: $i_{a}=I, i_{b}=-I, i_{c}=0, e_{a}=-e_{b}=\mathrm{E}_{m}$. From (2) the expression of the electromagnetic torque becomes:

$$
T_{e m}=\frac{2 . e . I}{\Omega}
$$

We have: $E_{m}=K_{e} \cdot \Omega$. So:

$$
\mathrm{T}_{\mathrm{em}}=2 \mathrm{~K}_{\mathrm{e}} \cdot \mathrm{I}=\mathrm{K}_{\mathrm{t}} \cdot \mathrm{I}
$$

Replacing in the system mechanical Equation (15):

$$
\mathrm{T}_{\mathrm{em}}=\mathrm{J} \frac{\mathrm{d} \Omega}{\mathrm{dt}}+\mathrm{B} \Omega+\mathrm{T}_{\mathrm{L}}
$$

Wefind:

$$
I=\frac{J}{K_{t}} \frac{d \Omega}{d t}+\frac{B}{K_{t}} \Omega+\frac{T_{L}}{K_{t}}
$$

Which gives:

$$
\frac{d I}{d t}=\frac{J}{K_{t}} \frac{d^{2} \Omega}{d t^{2}}+\frac{B}{K_{t}} \frac{d \Omega}{d t}
$$

Replacing (17) in (8) 


$$
\frac{d^{2} \Omega}{d t^{2}}=\frac{U_{a b}}{c_{1}}-\frac{c_{2}}{c_{1}} \frac{d \Omega}{d t}-\frac{c_{3}}{c_{1}} \Omega-\frac{c_{4}}{c_{1}}
$$

with

$$
c_{1}=\frac{L J}{K_{t}}, c_{2}=\frac{R J+L B}{K_{t}}, c_{3}=\frac{R B}{K_{t}}+K_{t} \text { and } c_{4}=\frac{R T_{L}}{K_{t}}
$$

The sliding surface is chosen as:

$$
S=\frac{d e}{d t}+K_{1} e
$$

Wheree $=\omega_{\mathrm{r}}-\omega$ is the error in speed.

$$
\begin{aligned}
& \dot{S}=\frac{d^{2} e}{d t^{2}}+K_{1} \frac{d e}{d t} \\
& \dot{S}=\sigma\left(\Omega, \frac{d \Omega}{d t}\right)-\frac{U}{C_{1}}
\end{aligned}
$$

With:

$$
\sigma\left(\Omega, \frac{\mathrm{d} \Omega}{\mathrm{dt}}\right)=\frac{\mathrm{d}^{2} \Omega_{\mathrm{r}}}{\mathrm{dt}^{2}}+\mathrm{K}_{1} \frac{\mathrm{d} \Omega_{\mathrm{r}}}{\mathrm{dt}}+\left(\frac{c_{2}}{c_{1}}-\mathrm{K}_{1}\right) \frac{\mathrm{d} \Omega}{\mathrm{dt}}+\frac{c_{3}}{c_{1}} \Omega+\frac{c_{4}}{c_{1}}
$$

Finally the command applied, has the form of Equation (12), with: $\lambda_{1}=2, \lambda_{2}=1.1$ and $L=0.2$

\section{EXPERIMENT RESULTS}

In all experiences BLDC motor with axial flux is used, $3 \mathrm{KW}, 80 \mathrm{~V}, 8$ poles Figure 4 , an inverter which can operate at $12 \mathrm{kHz}$ maximal switching frequency, a dSPACE card DS1104 operating at $20 \mathrm{MHz}$ and a PC with Control Disk interface for data acquisition.

To evaluate the effectivness of the Super Twisting algorithm in terme of speed reference tracking and solving the chattering problem, we performed several tests. In the first test we evaluated the response of the Super-Twisting controller (STC) to a speed reference of $1500 \mathrm{rpm}$ Figure 5, and we compared its response to that of a conventional sliding mode controller Figure 6, results show that the Super-Twisting controller solves the chattering problem that appears in conventional SMC and consequently improve the static regime ensuring a static error of $0.2 \%$ and a response time of $0.12 \mathrm{~s}$, it should be noted that the motor at the beginning is at rest. Figure 7 and Figure 8 give respectively the ST and SMC outputs, they show that the super twisting command is smooth contrary to the conventional sliding mode command which has a discontinuous form causing the Chattering problem and leading to indiserable effects at actuators. Figure 9 illustrates the slip variable behavior and its derivative, they effectively converge both to zero, which confirms that the objective of the command law is ensured. Figure 10 present Hall Effect sensor signals.

In the second test we imposed a variable speed reference, at the beginning the motor is at rest, and then the reference set up to $1500 \mathrm{rpm}$ before passing to $2500 \mathrm{rpm}$, the response of the super twisting controller and its generated command are given in Figure 11 and Figure 12 respectively. The last test was performed to visualize the behavior of the controller after the application of a $15 \mathrm{~V}$ perturbation in the power supply level. Figure 13And Figure 14 illustrate the perturbation impact on speed and respectively the controller reaction in order to be adapted to this abrupt change. 


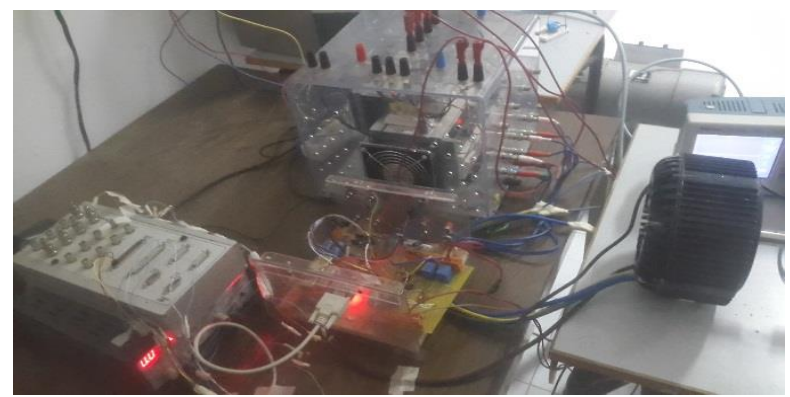

Figure 4. Experimental platform of system

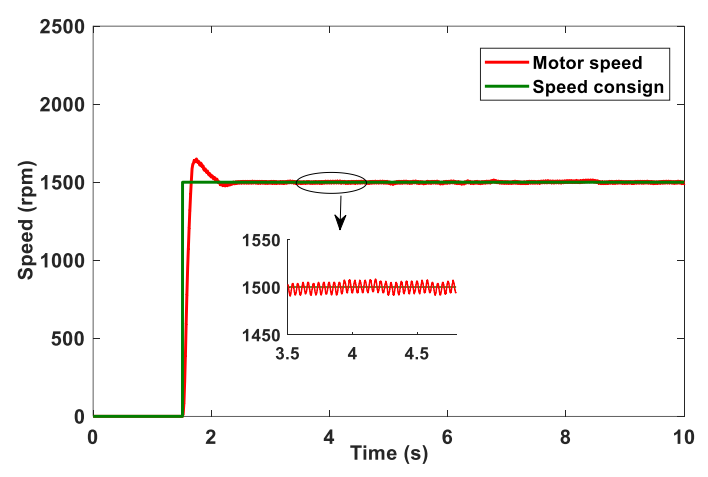

Figure 5. STCSpeed response

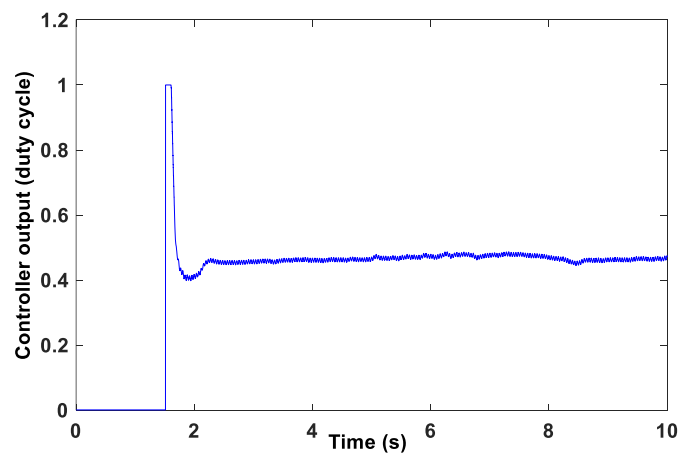

Figure 7. STC output

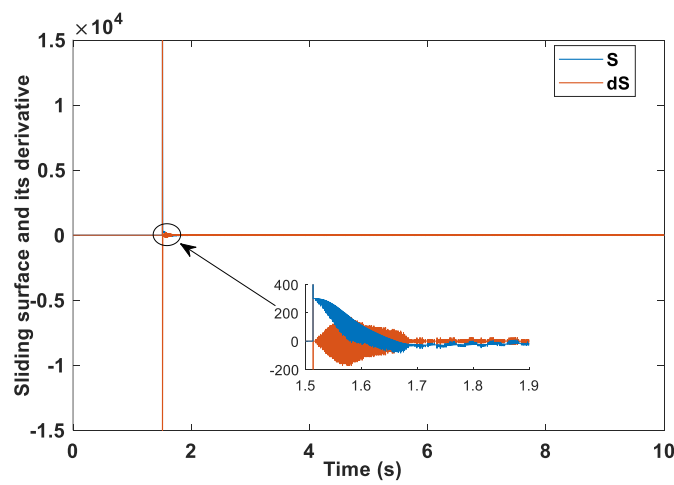

Figure 9. Sliding variable and its derivative

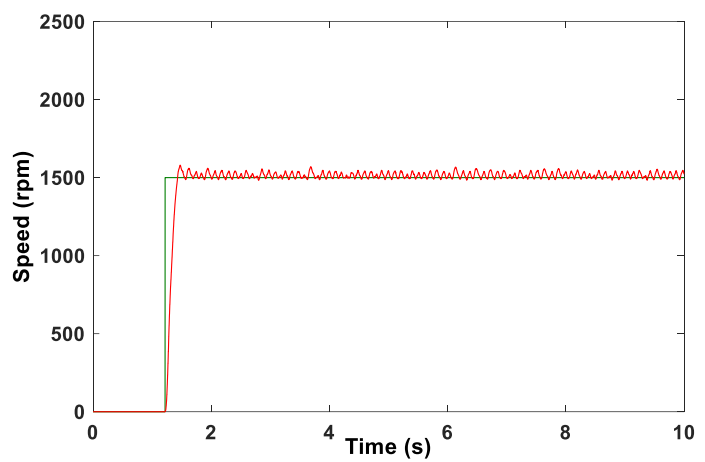

Figure 6. SMCspeed response

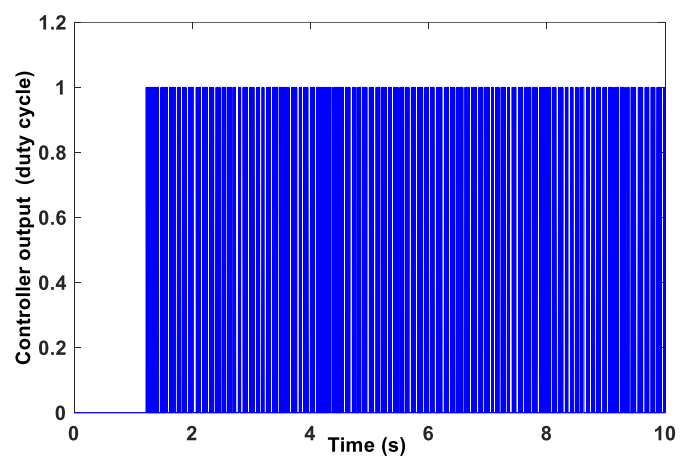

Figure 8. Conventional SMC output

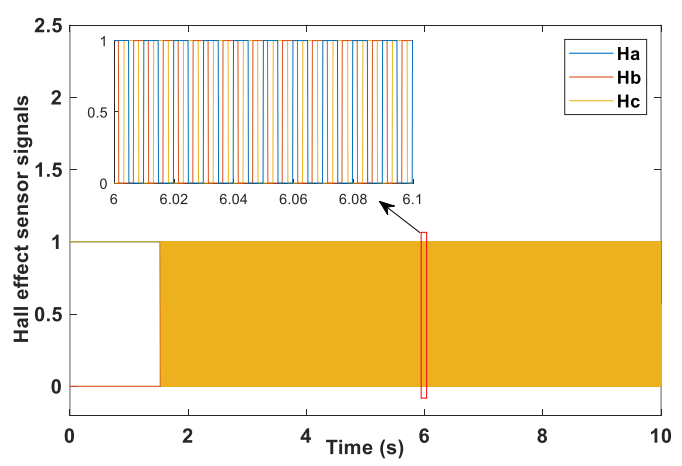

Figure 10. Hall Effect sensor signal 


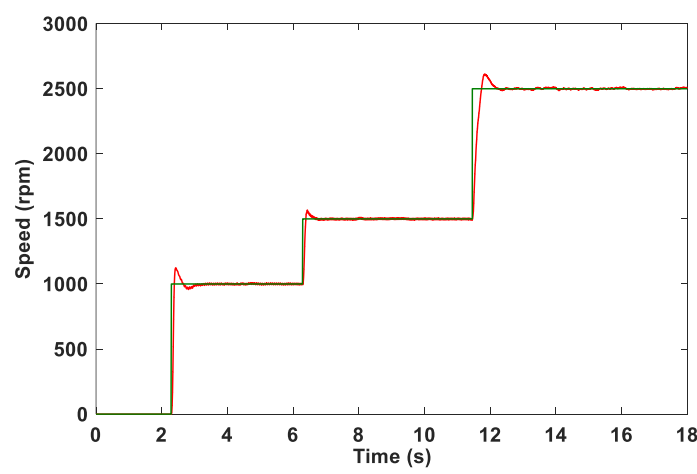

Figure 11. STCresponse to a variable consign

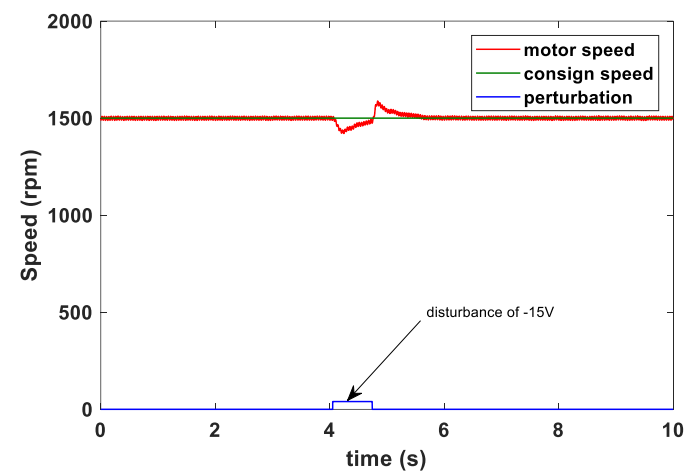

Figure 13. Reaction against a disturbance

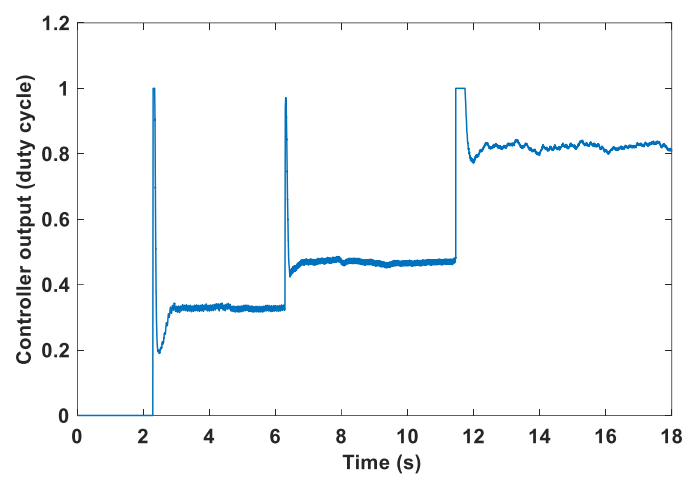

Figure 12. STC output

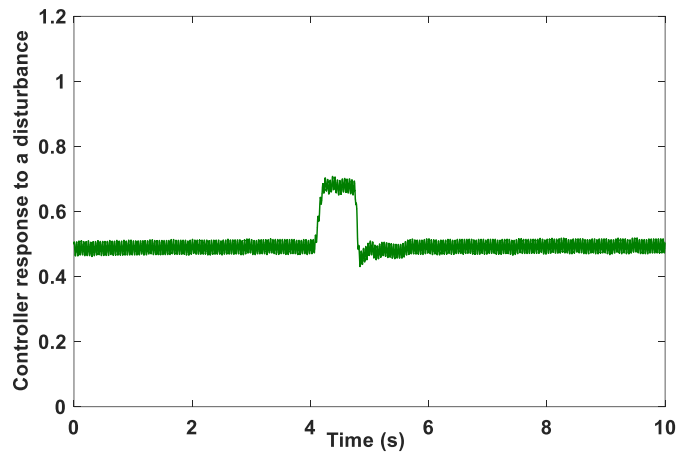

Figure 14. STC output

\section{CONCLUSION}

This paper proposes a non-linear control method based on Super-Twisting algorithm for BLDC motor speed control. This method which is a part of high order sliding mode commands, preserves all advantages of the conventional sliding mode control and allows to suppress the chattering phenomenon due to its discontinuous form by only requiring information on the sliding surface. In this context, after the electric modeling of the BLDC motor, the paper determines a command law to control it using the Super-Twisting algorithm. The proposed controller is implemented in dSPACE 1104 card for speed control of a BLDC motor $3 \mathrm{KW}, 80 \mathrm{~V}, 3000 \mathrm{rpm}$. Finally, the experimental results are compared with thoses of a conventional sliding mode controller, to show the effectiveness of the proposed control to concel the chattering phenomenon, and its performances in terme of static precision and fast response.

\section{ACKNOWLEDGEMENTS}

The authors would like to acknowledge the financial support of the national center for scientific and technical research in morocco (CNRST).

\section{REFERENCES}

[1] Y. Shi, et al., "A new approach of minimizing commutation torque ripple for blushless dc motor based on dc-dc converter," IEEE Trans. Ind. Electron., vol/issue: 57(10), pp. 3483-3490, 2010.

[2] P. Agrawal, et al., "Comparative study of fuzzy logic Based Speed Control of Multilevel Inverter fed Brushless DC Motor Drive," International Journal of Power Electronics and Drive System (IJPEDS), vol/issue: 4(1), pp. 70-80, 2014.

[3] J. S. Park and K. D. Lee, "Design and implementation of BLDC Motor with Integrated Drive Circuit," International Journal of Power Electronics and Drive System (IJPEDS), vol/issue: 8(3), pp. 1109-1116, 2017.

[4] M. A. Shamseldin et al., "Performance Study of Enhanced Non-Linear PID Control Applied on Brushless DC Motor," International Journal of Power Electronics and Drive System (IJPEDS), vol/issue: 9(2), pp.536-545, 2018.

[5] L. P. Guo, et al., "Comparative evaluation of sliding mode fuzzy controller and PID controller for a boost converter," ElectricPower Systems Research, vol/issue: 81(1), pp. 99-106, 2011. 
[6] C. Yan, et al., "Implementation of a PSO based Online Design of an Optimal Excitation Controller," 2008 IEEE Swann Intelligence Symposium, pp. 1-7, 2008.

[7] M. A. Fnaeich, et al., "Fuzzy logic and sliding-mode controls applied to sex-phase induction machine with open phases," IEEE Trans. Ind. Electron., vol/issue: 57(1), pp. 354-364, 2010.

[8] H. S. Choi, et al., "Global sliding-mode control improved design for a brushless DC motor," IEEE Control Systems Magazine, vol. 21, pp. 27-35, 2001.

[9] M. Habbab, et al., "Real time implementation of a fuzzy adaptative PI-sliding mode controller for Induction machine control," International Journal of Electricaland Computer Engineering (IJECE), vol/issue: 8(5), pp. 2883$2893,2018$.

[10] V. Bregeault, "Quelques contributions à la théorie de la commande par modes glissant," Laboratoire IRCCyN, Ecole Central de Nantes, 2010.

[11] V. Utkin, et al., "Sliding Mode Control in Electromechanical Systems," Systems and Control. Taylor \& Francis, London, 1999.

[12] V. Utkin, "Sliding Modes in Control Optimization," Springer, Berlin, 1992.

[13] V. Utkin, "Sliding Mode Control in Electro-Mechanical Systems," CRC Press, Second edition, Automation and Control Engineering, 2009.

[14] J. A. Burton and A. S. I. Zinober, "Continuous approximation of variable structure control," Int. J. Systems Science, vol/issue: 17(6), pp. 875-885, 1986.

[15] A. Levant, "Sliding order and sliding accuracy in sliding mode control," Int. J. Control, vol/issue: 58(6), pp. 1247-1263, 1993.

[16] A. Levant, "Homogeneity approach to high-order sliding mode design," Automatica, vol/issue: 41(5), pp. 823-830, 2005.

[17] A. Bacciotti and L. Rosier, "Liapunov functions and stability in control theory," Lecture notes in control and information sciences, Springer, 2001.

[18] A. Levant, "Principles of 2-sliding mode design," Automatica, vol. 43 pp. 576-586, 2007.

[19] S. Di Genaro, et al., "Sensorless high order sliding mode control of induction motors with core loss," IEEE Transactions on Industrial Electronics, vol/issue: 61(6), pp. 2678-2689, 2014.

[20] B. Beltran, et al., "Second-order sliding mode control of a doubly fed induction generator driven wind turbine," IEEE Trans. Energy Convers, vol/issue: 27(2), pp: 261-269, 2012.

[21] J. Liu, et al., "Adaptivegain second-order sliding mode observer design for switching power converters," Control Engineering Practice, vol/issue: 30(9), pp. 124-131, 2014. 